le portiQue $\begin{array}{ll}\text { Le Portique } \\ \text { Revue de philosophie et de sciences humaines }\end{array}$

33 | 2014

Straub !

\title{
Autour de trois films
}

Jean-Marie Straub

\section{(2) OpenEdition}

\section{Journals}

\section{Electronic version}

URL: http://journals.openedition.org/leportique/2762

DOI: 10.4000/leportique.2762

ISSN: $1777-5280$

\section{Publisher}

Association "Les Amis du Portique"

Printed version

Date of publication: 1 May 2014

ISSN: 1283-8594

\section{Electronic reference}

Jean-Marie Straub, "Autour de trois films", Le Portique [Online], 33 | 2014, document 5, Online since 05 February 2016, connection on 12 April 2021. URL: http://journals.openedition.org/leportique/2762 : DOI: https://doi.org/10.4000/leportique.2762

This text was automatically generated on 12 April 2021.

Tous droits réservés 


\title{
Autour de trois films
}

\author{
Jean-Marie Straub
}

1 Jean-Marie Straub - Sur Othon, je ne vous dirai qu'une chose. Avec des amis à Vienne, à l'époque, en travaillant, en répétant le texte, on rigolait en disant: voilà une lettre ouverte à Pompidou. Quant au Cézanne, je ne vous dirai pas un mot parce que c'est clair comme de l'eau de roche. J'ai deux choses à dire sur deux autres films différents. Il y en a un, par hasard qui s'appelle Le Fiancé, la Comédienne et le Maquereau. Vous l'avez vu, certains d'entre vous l'ont vu. Mais je tiens à préciser des trucs parce que ça me paraît un peu utile. C'est un film qui est constitué de quatre blocs. Le premier bloc: sur un pupitre de la Poste principale à Munich, c'est écrit, c'est gravé avec énergie et passion, Stupid Old Germany, stupide vieille Allemagne; I hate it all over here, je hais tout ici, partout ; I hope I can go soon, j'espère que je peux m'en aller bientôt. Voilà. Et c'est signé Patricia. Le film commence comme ça. Donc, c'est une femme. Une femme. Ensuite, on retrouve des femmes dans le brouillard et dans la nuit, dans l'ombre, le long d'un trottoir de la périphérie de Munich. Ces femmes-là font le trottoir, comme on dit. Derrière, il y a l'activité industrielle. C'est plein de trucs « publicitaires », câbles, etc. Et devant, il y a un trafic automobile intense, des camions, des voitures de luxe, même. C'est muet. Et ensuite, intervient quelque chose qui tombe du ciel, au milieu de ça, exactement au milieu de ce morceau de film muet. Ce qui intervient, c'est chanté en allemand. Et c'est quelque chose d'extrêmement glorieux. C'est quelque chose d'extrêmement glorieux et le texte: " $O$ jour, quand seras-tu que nous puissions saluer le Sauveur et que nous puissions l'embrasser, le baiser ». Ensuite, ça s'arrête et on voit des gens qui manigancent. C'est du théâtre et c'est une série de petits comportements intellectuels bourgeois. Il y en a un là-dedans qui dit :" Lucie est une créature géniale, je pourrais la porter, la conduire sur le trottoir". Quand c'est fini, il y a du cinéma qui commence, du vrai cinéma, du bête cinéma. Il y a une voiture qui part, une autre voiture qui la suit. Il y a une voiture qui se fait poursuivre par une autre voiture. Ça s'arrête en dessous d'un pont, en bas d'un talus, avec une rivière qui est un torrent. Les deux qui se poursuivent sont censés traverser le torrent, ils se rejoignent de l'autre côté, et l'un se fait précipiter dans le vide par l'autre. Celui qui a précipité l'autre dans le vide, c'est une créature noire, américaine, qu'on découvrira ensuite. Ensuite, on voit une campagne. Il y a une campagne, et on voit une voiture arriver de loin, des champs, 
tout ça à l'air très paisible, presque bucolique. La voiture s'arrête devant une petite maison de banlieue. Il y a deux personnages qui en sortent dont un est un noir, l'autre est de nouveau une femme, on retrouve la femme. Parce que c'est un film tout à fait féministe. C'est même le seul film féministe de toute l'histoire du cinéma. Cette femmelà sort et l'autre lui met un manteau sur les épaules, très galamment. Et il récite un poème. Il dit: "Da nun die Zeit war gekommen" (05 52); le rachat de la fiancée, qui servait sous un joug dur, Moïse lui donna la loi de Moïse. Après quoi elle répond, avec un autre poème du même auteur, qui est un espagnol qu'elle nous a traduit mot à mot. Et il se trouve que c'est un mystique espagnol qui s'appelle Saint-Jean de la Croix. Et elle répond. - Donc, on revient au début du film, avec le marché qui a inauguré le film «Sur la place du marché, dites que je ne suis plus là et que j'ai été perdue et qu'en me perdant, j'ai été gagnée ». Après quoi il y a un coup de feu. Alors, la musique qui intervient n'est pas du tout ce que disait Jacques Drillon, personnage très intelligent que nous avons eu ici pour une conférence, une table ronde. C'est quelque chose qui a introduit un coup de vent, et qui a introduit quelque chose de l'extérieur, qui introduit une sorte de révolution mystique. Alors, tout le film, c'est un film mystique. Et ensuite, elle récite un dernier poème qui est un poème d'amour fou, carrément d'amour fou, où elle parle des trois machines du monde qui ne sont rien du tout en comparaison de son amour. Voilà. Il vaut mieux voir le film comme ça parce que c'est un film policier par ailleurs. C'est quatre blocs qui constituent, qui racontent vraiment une intrigue policière sur la femme. Voilà. C'est un truc que je voulais quand même préciser. Est-ce qu'il y a des questions là-dessus.

Spectateur - On voudrait bien revoir le film.

3 J.-M. S. - Ça, je ne sais pas. Nous sommes dans une entreprise qui est une organisation gigantesque qui dépend de Pompidou, auquel est dédié Othon! Ça me paraît difficile. F. G. - (Ciné Art) : Est-ce qu'après le film Cézanne, on pourrait revenir sur le film?

5 J.-M. S. - Ça n'a aucun intérêt. Cézanne, c'est Cézanne. Moi, je fais tout ce que tu veux. Je suis là, je suis du bois dont on fait les flûtes. Quand il y a des films qui s'arrêtent, tu dis : "Maintenant, on s'arrête et on va dehors et on aura la discussion après ". Ça dure dix minutes. On n'a même pas le temps de placer un mot sur le film. Là, tout d'un coup, tu veux me faire parler sur Cézanne. Donc, pour te faire plaisir, je parlerai sur Cézanne.

6 F. G. - Cézanne, c'est le film qu'on va voir maintenant.

7 J.-M. S. - Bon, on le voit et puis c'est tout. Les films ne sont pas faits pour discuter dessus. Ils sont faits pour être vus. Maintenant, j'ai encore quelque chose à dire sur l'autre film qu'on a vu, parce que là aussi, tu m'as reproché de ne pas parler. En effet. Je regrette. Moi j'étais encore en haut parce que je n'avais pas la force de descendre l'escalier. Je m'étais retrouvé avec un film que j'avais oublié, que j'avais voulu voir ici et que grâce à vous, j'ai pu revoir. Je vous en remercie humblement. Je l'ai vu, et dès le début, ce qui m'arrive rarement au cinéma, j'avais les yeux complètement humides. Je ne dis pas que j'ai versé de grosses larmes, non, des larmes de crocodile. Mais j'avais les yeux humides du début à la fin.

8 F. G. - On peut préciser que c'est Le 6 juin à l'aube de Jean Grémillon, film qu'on a passé mardi au Caméo.

9 J.-M. S. - Maintenant, ce film-là, pourquoi je n'ai pas voulu en parler ? Parce que quand on a été ému, on n'a pas envie de raconter des conneries. Voilà. Maintenant, comme on en reparle, je tenais à placer deux mots là-dessus. Pourquoi ce film-là m'a-t-il ému ? 
Parce que d'abord, je l'ai redécouvert, et quand on voit un film après 15 ou 20 ans, on s'aperçoit qu'on ne l'avait vraiment pas vu. Et deuxièmement, c'est ce que j'ai découvert là-dedans : j'ai découvert que nos libérateurs et nos amis américains ont commencé par nous détruire. S'ils nous ont détruits, ce n'est pas un hasard. Ils n'avaient qu'une idée en tête, c'était de coloniser l'Europe, d'implanter le plan Marshall et d'imposer McCarthy et d'interdire les partis communistes dans tous les pays d'Europe. Et ensuite de reconquérir l'Europe de Goebbels jusqu'à l'Oural. Et on y est arrivé. Et on a fait ce travail-là avec eux, en les aidant. Et nous avons tous été bouffés par le colonialisme américain. Et comment le colonialisme américain a-t-il commencé ? Il a commencé le 6 juin à l'aube. Et avec quels moyens ? On l'a vu. Moi qui étais un petit con à l'époque, j'avais une mansarde chez mes parents, dans le grenier, j'avais une carte de la Normandie, j'avais des petites épingles et des petits drapeaux. Pendant toute la campagne en question, après le débarquement, je déplaçais les drapeaux en voyant la progression des alliés. Des alliés! Et ça me faisait du baume au cœur. Eh bien, j'ai découvert que j'avais été trompé comme un gamin, comme on trompe tous les gamins. Voilà. Et que je m'étais fait avoir. Donc, ça m'a fait un choc terrible. Je le savais. Mais là, je l'ai vu concrètement, parce que le film est concret. Maintenant, si c'est ça que j'aurais dû dire l'autre soir, et bien ce n'était vraiment pas de mise après que le film avait eu lieu. Voyez Cézanne calmement, et après, vous me ferez faire tous les discours que vous voulez. Je suis du bois dont on fait les flûtes ! 